\title{
Palaeozoic palaeodictyopteran insect nymphs with prominent ovipositors from a new locality
}

\author{
Christine Kiesmüller, Marie K. Hörnig, Angelika Leipner, Carolin Haug \& \\ JOACHIM T. HAUG
}

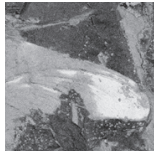

\begin{abstract}
Palaeodictyopteran insects (ingroup of Palaeodictyopteroidea) are exclusively fossil palaeopterous insects, representing an important faunal component in the late Palaeozoic. Fossils of palaeodictyopteran insects are still rather rare, and especially their ontogeny is still very incompletely known. Here new findings of palaeodictyopteran nymphs from the Piesberg quarry, Osnabrück, are reported. The examined specimens include three more or less complete specimens and three nymphal terga with pronounced wing anlagen of which one shows both meso- and metanotal wing anlagen, and the other two represent isolated mesonota. These findings most likely represent an ontogenetic sequence. The specimens described herein are of the Rochdalia-type of palaeodictyopteran nymphs, being extremely similar to these especially concerning the pronotum, wing anlagen and abdomen morphology. As a remarkable observation, the here described, very complete fossils possess large posterior pointing structures. These are interpreted as ovipositors. The pattern of wing anlagen development and the presence of a large ovipositor support the supposed gradualness of the development of palaeodictyopteran insects. The massiveness and morphology of the ovipositor furthermore indicates that eggs were laid into plants and were most likely rather large and yolk-rich. - Key words: Palaeodictyopteroidea, nymphal development, Carboniferous, Moscovian, Piesberg quarry, Rochdalia.
\end{abstract}

\begin{abstract}
Kiesmüller, C., Hörnig, M.K., Leipner, A., Haug, C. \& Haug, J.T. 2019. Palaeozoic palaeodictyopteran insect nymphs with prominent ovipositors from a new locality. Bulletin of Geosciences 94(1), 23-40 (9 figures, 2 tables). Czech Geological Survey, Prague. ISSN 1214-1119. Manuscript received June 15, 2018; accepted in revised form March 5, 2019; published online March 31, 2019; issued March 31, 2019.

Christine Kiesmüller, Carolin Haug \& Joachim T. Haug, LMU Munich, Biocenter, Department of Biology II and GeoBio-Center, Großhaderner Str. 2,82152 Planegg-Martinsried, Germany; joachim.haug@palaeo-evo-devo.info • Marie K. Hörnig, Ernst-Moritz-Arndt-University of Greifswald, Zoological Institute and Museum, Cytology and Evolutionary Biology, Soldmannstr. 23, 17487 Greifswald, Germany • Angelika Leipner, Museum am Schölerberg, Klaus-Strick-Weg 10, 49082 Osnabrück, Germany
\end{abstract}

Insects have been supposed to represent the most diverse group of animals in extant and past times ( $c f$. Grimaldi \& Engel 2005, but see e.g. Haug et al. 2016 for the logical incorrectness of this statement). With first appearances in the Devonian (ca. 400 million years ago; e.g. Labandeira et al. 1988) their massive diversification began in the Carboniferous (around 360-300 million years ago) near the end of the Palaeozoic (e.g. Kukalová-Peck 1971, Wootton 1981).

The enormous extant species richness (and individual richness) is unsurprisingly also reflected in the fossil record of insects to a certain extent. The majority of fossil insects in the Carboniferous seem to represent isolated wings; this part of the insect body seems to possess the best preservational capabilities ( $c f$. Rasnitsyn \& Quicke 2002, Grimaldi \& Engel 2005).

Very abundant insect groups in the Carboniferous were representatives of Dictyoptera sensu lato and palaeodictyopteroideans (e.g. Carpenter 1992). Palaeodictyopteroidea is an extinct group of palaeopterous insects (Carpenter \& Burnham 1985 and references therein); currently it remains partly unclear if the group is monophyletic (a recent analysis by Sroka et al. 2015 found a monophyletic group, there termed Palaeodictyopterida). Palaeodictyopteroideans were middle-sized to large insects with a wing span up to over $500 \mathrm{~mm}$ (Rasnitsyn \& Quicke 2002, Grimaldi \& Engel 2005). They possessed pronounced meso- and metathoracic wings, but additionally paranotal lobes drawn out from the pronotum that probably had a flight stabilizing function (Kukalová 1969a, 1970; Wootton \& Kukalová-Peck 2000). Their wings have been interpreted as most "primitive" or better, less derived of all palaeopterous insects with a rather simple wing venation, i.e. less branching and 'with either rich archedictyon or numerous cross-veins' (Rasnitsyn \& Quicke 2002, cf. also Kukalová 1970). The majority of 
palaeodictyopteroideans are only known by isolated wings or wing fragments (e.g. Kukalová 1969a, 1969b, 1970; Kukalová-Peck 1971; Brauckmann \& Hahn 1978; Brauckmann 1995; Brauckmann \& Herd 2002; Prokop \& Ren 2007; Brauckmann et al. 2009). Comparably few specimens preserved with major parts of their bodies have been reported (e.g. Kukalová-Peck 1971, Brauckmann 1991, Ross 2010, Pecharová et al. 2015).

Even fewer specimens were found with their head still attached and additionally also revealing their mouthparts, but these provide sufficient insights. The mouthparts appear to have formed a beak-like structure; based on this morphology and the stomach content of one specimen, it has been concluded that they seem to have sucked on plant juices (compare Kukalová 1970, Kukalová-Peck 1972, Labandeira \& Phillips 1996). The very posterior side of Palaeodictyopteroidea has been similarly less often described, due to the same reasons as before, but there were some findings of female and male genitalia. Males and females appear to have very long cerci (two times of abdomen). In some groups terminal claspers were described for males (Prokop et al. 2016a and references therein). Females possess an ovipositor (Prokop et al. 2016a and references therein) which has been described as smaller, sometimes a little triangular as is seen in Orthoptera (e.g. Kukalová 1970, Brauckmann 1991), slightly curved (Kukalová 1969b, Kukalová-Peck 1971) or even long with sharp scissor-like edges (Brauckmann 1991). During the Permian the abundances of palaeodictyopteroideans dropped until they became most likely extinct at the end of the Permian (the identity of a Triassic palaeodictyopteroidean by Béthoux et al. 2010 has been criticised by Shcherbakov 2011).

While the view on the adult biology of adult palaeodictyopteroideans is incomplete, even less is known about their ontogeny. Only in few instances nymphal stages of palaeodictyopteroideans have been reported (Carpenter 1948; Richardson 1956; Rolfe 1967; Wootton 1972; Kukalová-Peck \& Peck 1976; Ross 2010; Prokop et al. 2013, 2017a, 2018; see Haug et al. 2016 for a recent review). Nymphs appear still to be rare among the Palaeozoic insect fossils and identifying them as representing a palaeodictyopteroidean remains challenging as the majority of adult characters for identifying a palaeodictyopteroidean (or its in-groups) are based on wing characters which cannot be easily applied to nymphal wing anlagen.

Here we report findings of 308 million years old female palaeodictyopteroidean nymphs, more exactly of the ingroup Palaeodictyoptera, from the Piesberg quarry (north western Germany). These show exceptional preservation of overall body structures including massive presumable ovipositors. The possible impacts on palaeodictyopteroidean developmental and breeding biology are discussed.

\section{Material and Methods}

Material. - The here described specimens (overview Fig. 1) with the collection numbers Pal. 1242 and Pal 709 come from the palaeontological collection of the Museum am Schölerberg (MaS Pal), Osnabrück. The numbers F208, F246, F133, F134 and F136 are from the collection of Michael Sowiak, Glandorf, Germany. His fossils are now in the possession of the Naturwissenschaftlicher Verein Osnabrück and will be deposited in the collections of the Museum am Schölerberg. The fossils were found in the Piesberg quarry near Osnabrück, in the roof shales of the coal seam Dreibänke (middle Pennsylvanian, latest Moscovian which corresponds to Westfalian D; detailed descriptions of geology of the Piesberg quarry, $c f$. Josten et al. 1984 and also Dunlop et al. 2008). It is worth mentioning that all here described fossil nymphs and further nymphs are from a single area of about 30 square metres. Other areas of the Piesberg quarry possess only very few nymphal specimens and mostly in a worse preservation.

Methods. - All specimens were photographed with a Canon Eos Rebel T3i, equipped with a MP-E $65 \mathrm{~mm}$ objective and a Canon MT 24 Macro Twin Flash. In order to reduce reflections and enhance the contrast between fossil and matrix, all specimens were photographed under cross-polarised light (cf. Haug et al. 2008, 2009, 2011; Kerp \& Bomfleur 2011; Hörnig et al. 2014).

All images were optimised for colour balance, saturation and sharpness in Adobe Photoshop CS2 and CS4. Adobe Photoshop CS2 and Adobe Illustrator CS2 was also used to colour-mark the images and drawings. Terminology follows neutral arthropod terminology, special insect terminology is pointed out where necessary.

\section{Results}

\section{Description of Pal. 1242}

The specimen represents a palaeodictyopteran nymph in dorsal aspect (part in Fig. 2 and counterpart in Fig. 3) with a preserved total length (as in Fig. 2) of $49.9 \mathrm{~mm}$. It is most likely an exuvia, as mostly only one half of the animal is preserved, when it probably broke free from medio-dorsal where a former suture is visible. As the specimen represents an insect it should have been originally organised in three major tagmata; the head (caput) and a bipartite trunk, with thorax and abdomen.

The head (ocular segment and post-ocular segments $1-5)$ and thoracic legs are not visible due to preservation. The thorax (pro-, meso- and metathorax; post-ocular segments 6-8) is almost completely preserved (one half). 


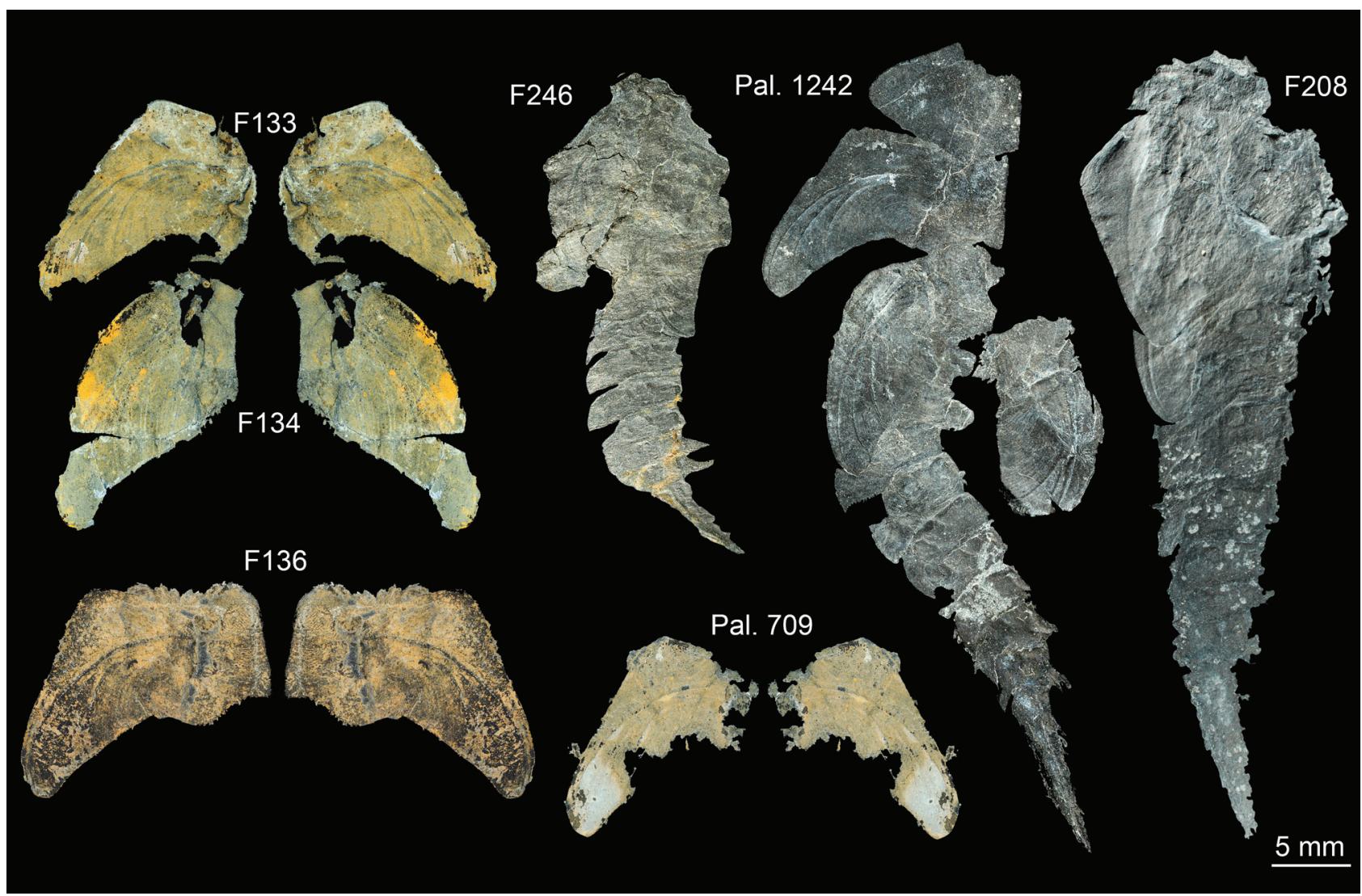

Figure 1. Rochdalia-type insect nymphs from the Piesberg quarry. All specimens used in this study are in the same scale to reveal relative sizes. Isolated wings were doubled and mirrored.

All three segments have a well sclerotised tergite each (pronotum, mesonotum, metanotum), which are drawn out laterally into lobe-like extensions.

The pronotum is of trapezoid/trapezium shape in dorsal view, with gently rounded corners and with a slight cavity anteriorly and an overall resemblance to an arrowhead. The surface near the anterior cavity is slightly granular, only on the anterior side and only on the counterpart (Fig. 3). The counterpart also seems less smooth on the surface compared to the part (Fig. 2), but wrinkly especially on its posterior. It is twice as wide (on its widest region) as long (absolute values in Tab. 1, as for all following thoracic segments).

The mesonotum (in dorsal view) is more rectangular centrally with a posteriorly curving tip of its wing anlage and a pronounced wing venation. The wing anlage arises laterally of the rectangular central part of the tergite, as a lobe-like extension. Its anterior edge runs first abaxially but then curves back at a sharp angle (nearly $90^{\circ}$ ). The posterior edge gently curves backwards with a more rounded shape posteriorly. There are three major veins visible curving from one point in the anterior median, spreading slightly towards the tip of the wing anlage. These veins seem to protrude from the surface. The veins themselves do not seem to be connected; it is unclear whether this is the original condition or caused by preservation. There are only indications of other veins on the posterior medio-lateral part of the tergite (closer to the suture than the major veins) which seem to be parallel to each other and the three major veins. The anterior lateral part of the mesonotum shows (in the counterpart, Fig. 3) a slightly wrinkly surface, but this is only visible under certain viewing angles, wherein the surface in other angles appears smooth (Fig. 2). This same pattern corresponds with wrinkly surface of the posterior part of the pronotum. The tip of the wing anlage is also covered with a paler mineral than the rest of the fossil, possibly being organic residuals. The length of wing anlage (WL in Fig. 4) is three times as long as the median line (L2 in Fig.4).

The metanotum is in dorsal view of comparable shape to the mesonotum with a few differences. Anteriorly it is more rounded without sharp edges as the anterior part of the mesonotum. Furthermore the metanotum is less curved posteriorly and straighter in shape than the mesonotum. There are three major veins visible, as in the mesonotum, and also indications of paralleling smaller veins (well visible on one side of the metanotum, on the other side it is not completely preserved; Figs 2,3 ). The 
visible vein pattern is similar to that of the mesonotum from the anterior median part towards the tips of the wing anlage, though more anteriorly than in the mesonotum. The surface of the metanotum appears in both parts less granular than the mesonotum, but due to the preservation it is difficult to discern surface structures of the fossil from its stone matrix. The metanotum is, also, nearly three times as long in the length of the wing anlage (WL in Fig. 4) as compared to the median line (L2 in Fig. 4).

Abdominal segments are mainly represented by their dorsal sclerites (tergites). The presumable first two abdominal segments (post-ocular segments 9-10) are partly covered by part of the metanotal wing anlage and therefore only partially visible. They are half as long as the pronotum (absolute measurements in Tab. 2, as well as for all following abdominal segments). The tergites of abdominal segments appear to have a slightly granular surface, especially in the counterpart. Abdominal segment 3 (post-ocular segment 11) is of rectangular shape and just slightly concealed by the metanotal wing anlage. Some part of it on its medio-lateral side presumably lacks due to preservation. The tergite of abdominal segment 3 has a lateral lobe-like protrusion on the left side (Fig. 2), a paranotal lobe, which is of trapezoid shape, directed slightly posteriorly and has tiny saw-like serrations posteriorly. The surface appears to be more or less smooth in both part and counterpart and it is four times wider than long. The tergites of abdominal segments 4 and 5 (postocular segments 12-13) show similar shape in general, yet, with a less prominent saw-like armature on the posterior edge. The tergite of abdominal segment 4 is twice as wide as long, as well as the tergite of abdominal segment 5 (post-ocular segment 13). The surface of the tergite of abdominal segment 4 differs between part and counterpart as on the counterpart it appears to have a smooth surface with only a few anterior-posterior directed cracks that come from anterior to midway through the notum. On the part it looks more like a wave rippled from anterior through the median part of it, making the surface wrinkly in a circular pattern on the median part of the wing anlage with exclusion of the lateral lobe which appears smooth. The tergite of abdominal segment 5, opposed to that, appears smooth with very slight wrinkles that also form wider circular patterns, extending from the preceding segment - probably due to the same reasons. Abdominal segments 6-9 (post-ocular segments 14-17) are also of

Table 1. Measurements [mm] of the presented fossils' wing pads according to Fig. 4, with additional measurements of the total preservational length of the more complete fossils (not consisting only of the wing pad) including the length of their presumable ovipositors. Abbreviations as in Fig. 4. Symbol: $-=$ not measurable.

\begin{tabular}{|c|c|c|c|c|c|c|}
\hline Specimen & $\begin{array}{l}\text { thoracic segments } \\
\text { (pr: prothoracic; } \\
\text { ms: mesothoracic; } \\
\text { mt: metathoracic) }\end{array}$ & $\begin{array}{l}\text { upper edge } \\
\text { of wing pad } \\
\text { (L1 in Fig. 4) }\end{array}$ & $\begin{array}{l}\text { median length } \\
\text { of tergite } \\
\text { (L2 in Fig. } 4 \text { ) }\end{array}$ & $\begin{array}{l}\text { diagonal length } \\
\text { from respective } \\
\text { outer points } \\
\text { of L1 and L2 } \\
\text { (D in Fig. 4) }\end{array}$ & $\begin{array}{l}\text { wing length } \\
\text { (WL in Fig. 4) }\end{array}$ & $\begin{array}{c}\text { total } \\
\text { preservational } \\
\text { length }\end{array}$ \\
\hline & $\mathrm{pr}$ & - & 4.8 & - & 10.3 & \multirow{3}{*}{49.9} \\
\hline \multirow[t]{3}{*}{ Pal. 1242 (Fig. 2) } & $\mathrm{ms}$ & 6.9 & 7.2 & 9.3 & 15.4 & \\
\hline & $\mathrm{mt}$ & 5.3 & 6.2 & 8.0 & 16.2 & \\
\hline & $\mathrm{pr}$ & - & 5.4 & - & 10.3 & \multirow{3}{*}{30.7} \\
\hline \multirow[t]{3}{*}{ Pal.1242 (Fig. 3) } & $\mathrm{ms}$ & 7.3 & 7.7 & 9.7 & 19.7 & \\
\hline & $\mathrm{mt}$ & - & - & - & 14.3 & \\
\hline & pr? & - & 4.7 & - & 6.5 & \multirow{3}{*}{47.4} \\
\hline \multirow[t]{2}{*}{ F208 (Fig. 5) } & $\mathrm{ms}$ & 5.4 & 5.4 & 7.2 & 13.5 & \\
\hline & $\mathrm{mt}$ & - & 2.0 & - & 7.5 & \\
\hline F246 (Fig. 6A, B) & $\mathrm{mt}$ & 2.7 & 2.9 & 3.7 & 8.9 & 27.4 \\
\hline F246 (Fig. 7C, D) & $\mathrm{mt}$ & 4.0 & 4.6 & 6.2 & 10.5 & 31.4 \\
\hline F133 (Fig. 7A, B) & $\mathrm{ms}$ & 8.0 & 7.8 & 9.3 & 14.4 & - \\
\hline F134 (Fig. 7A, B) & $\mathrm{mt}$ & - & - & - & 17.9 & - \\
\hline F 136 (Fig. 7C, D) & $\mathrm{ms}$ & 10.5 & 6.7 & 12.0 & 18.8 & - \\
\hline Pal 709 (Fig. 7E, F) & $\mathrm{ms}$ & 6.6 & 5.7 & 8.0 & 14.1 & - \\
\hline
\end{tabular}




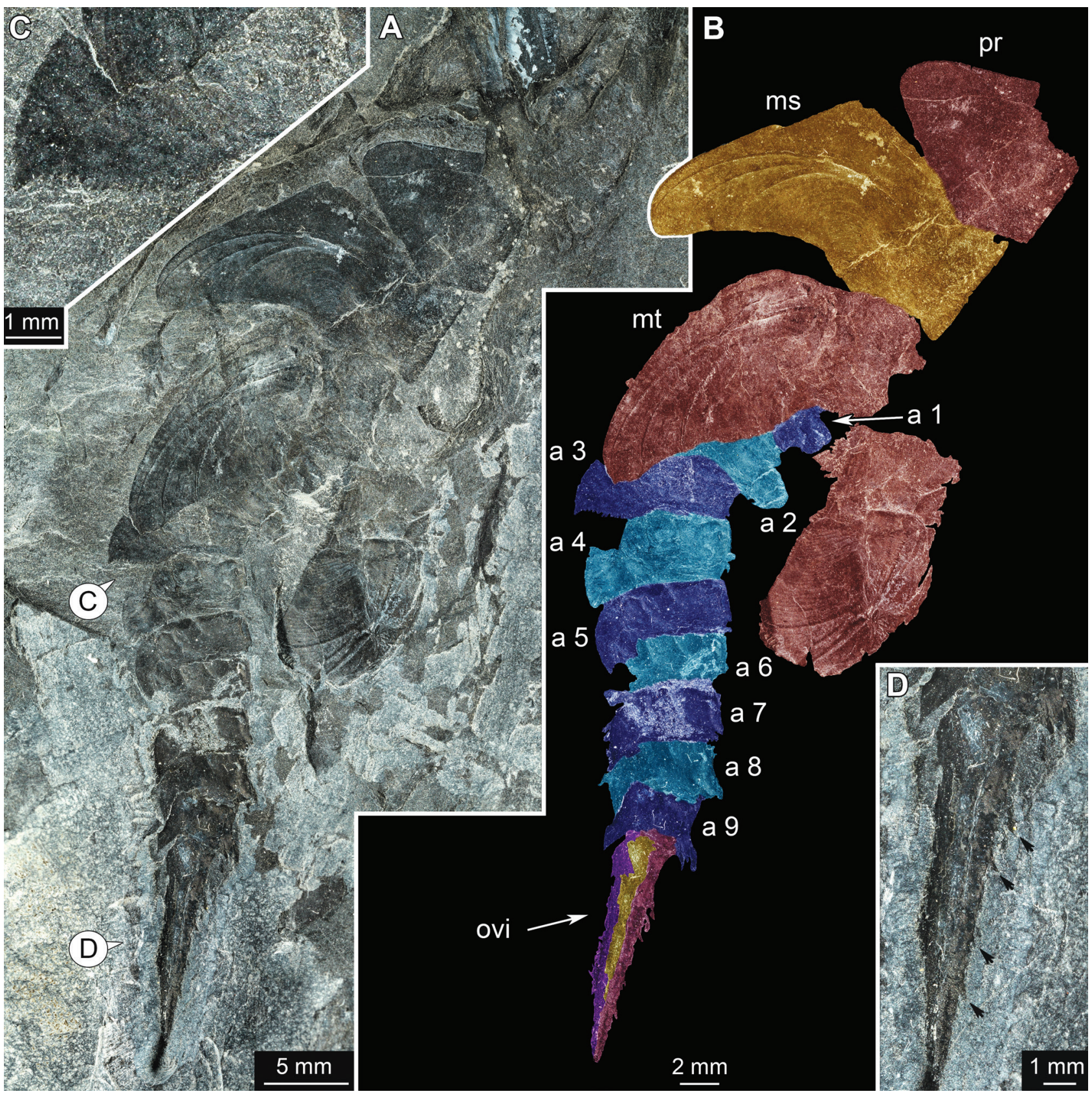

Figure 2. Rochdalia-type insect nymph from the Piesberg quarry. Part of MaS Pal. 1242; A - overview image; B - colour-marked version of A, in red and orange thoracic segments, in blue and cyan abdominal segments, other colours ovipositor valves (if distinguishable); $\mathrm{C}-\mathrm{close-up} \mathrm{of} \mathrm{first}$ visible abdominal paranotal lobe of abdominal segment 3; D - close-up of ovipositor; arrows mark serrations. Abbreviations: a - abdominal tergites; $\mathrm{pr}$ - pronotum; $\mathrm{ms}$ - mesonotum; $\mathrm{mt}$ - metanotum; ovi - ovipositor.

rectangular shape, though with even less pronounced paranotal lobes - without abdominal segment 6 (postocular segment 14) - and no saw-like serrated edge posteriorly. All (abdominal segments 6-9) are about twice as wide as long. Abdominal segments 8 and 9 (post-ocular segments 16 and 17) additionally also have paranotal lobes on their right hand side, though their overall shape differs from preceding segments. Where the preceding segment's paranotal lobes had a round, convex anterior shape, these two last, preserved segments have a more concave anterior shape of the paranotal lobes on both sides. Abdominal segment 8 (post-ocular segment 16) also appears to have a less well defined right hand side paranotal lobe, so with the sharp tip visible in the one on the other side (Fig. 2). This may indicate that only abdominal segment 9 (postocular segment 17) is preserved entirely, as it shows both paranotal lobes in nearly similar preservation, i.e. with a sharp tip. 
Table 2. Measurements [mm] of the abdomen of the more completely preserved specimens (Pal. 1242, F246 and F208). Including width and length of each abdominal segment and ovipositor measurements. Abbreviation: abd - abdominal segment. Symbols: $-=$ not measurable; $x=$ not preserved.

\begin{tabular}{|c|c|c|c|c|c|c|c|c|c|c|}
\hline maximum width & abd 1 & abd 2 & abd 3 & $\operatorname{abd} 4$ & abd 5 & abd 6 & abd 7 & abd 8 & abd 9 & ovipositor \\
\hline Pal. 1242 (Fig. 2) & - & - & 7.8 & 7.4 & 7.1 & 5.0 & 6.0 & 6.3 & 5.0 & 2.6 \\
\hline Pal. 1242 (Fig. 3) & - & - & 8.1 & 7.5 & 6.8 & $\mathrm{x}$ & $\mathrm{x}$ & $\mathrm{x}$ & $\mathrm{x}$ & $\mathrm{x}$ \\
\hline F208 (Fig. 5) & 9.4 & 11.5 & 8.8 & 8.6 & 8.6 & 6.5 & 6.6 & 7.0 & 6.0 & 2.8 \\
\hline F 246 (Fig. 6A) & - & 2.9 & 6.6 & 6.5 & 6.3 & 5.4 & 4.6 & $\mathrm{x}$ & $\mathrm{x}$ & 2.0 \\
\hline F246 (Fig. 6C) & - & 6.5 & 6.6 & 7.3 & 5.9 & 7.0 & 7.1 & $\mathrm{x}$ & $\mathrm{x}$ & 1.8 \\
\hline median length & abd 1 & abd 2 & abd 3 & $\operatorname{abd} 4$ & abd 5 & abd 6 & abd 7 & abd 8 & abd 9 & ovipositor \\
\hline Pal. 1242 (Fig. 2) & 2.9 & 2.3 & 2.8 & 3.1 & 2.6 & 2.4 & 3.0 & 2.4 & 2.5 & 12.4 \\
\hline Pal. 1242 (Fig. 3) & 3.0 & 2.1 & 3.0 & 3.0 & - & $\mathrm{x}$ & $\mathrm{x}$ & $\mathrm{x}$ & $\mathrm{x}$ & $\mathrm{x}$ \\
\hline F208 (Fig. 5) & 6.3 & 2.6 & 3.4 & 3.4 & 4.0 & 2.6 & 3.5 & 2.6 & 2.9 & 11.9 \\
\hline F 246 (Fig. 6A) & - & 1.9 & 2.4 & 2.1 & 1.8 & 1.4 & 1.4 & $\mathrm{x}$ & $\mathrm{x}$ & 6.5 \\
\hline F246 (Fig. 6C) & 2.8 & 2.0 & 2.1 & 2.3 & 2.1 & 1.8 & 1.5 & $\mathrm{x}$ & $\mathrm{x}$ & 7.1 \\
\hline
\end{tabular}

Presumably ventrally arising from abdominal segments 8 and 9 is an elongated triangular structure. This structure is about as long as the posterior five abdominal segments and is four times as long as its base wide (absolute measurements also in Tab. 2). The structure appears to be divided into three parts. The lateral edges appear to be serrated and of a darker colour than the median part. The surface of the structure seems more or less smooth. No additional structures of the further posterior abdominal segments are apparent.

\section{Description of F208}

The specimen represents a palaeodictyopteran nymph in slightly latero-dorsal aspect (Fig. 5) with a preserved total length of $47.4 \mathrm{~mm}$. The specimen is less completely preserved than Pal 1242, but similar in appearance. Mainly differences observed compared to Pal 1242 are pointed out.

Also here the head (ocular segment and post-ocular segments 1-5) and the thoracic legs are not visible, too, due to preservation. It is unclear whether a part of the pronotum is preserved; a candidate piece could for this also represent a part of the metanotum. Yet, it has a similar granular structure on it, though more postero-laterally than in Pal. 1242. These structures also appear to be larger than in Pal. 1242 and appear more like nubs than granules. The possible pronotum is 1.5 times as long as wide in dorsal view [absolute measurements in Tab. 1, as for all following thoracic measurements; here, as it is unclear to which segment it belongs, the absolute values were derived from measuring the anterior lying edge (as L2) and perpendicular to that the other measurement (as WL)]. Left(?) tergites of meso- and metanotum are either incompletely preserved or not at all.

The mesothoracic wing anlage is similar in general shape to that of Pal. 1242, though the angle at which it bends backwards is wider than in Pal. 1242 making it a softer angle. The posterior side of the wing anlage is also less curved than in Pal. 1242. Both aspects might be caused by the slightly different orientation of the specimen. The venation is less well preserved; of the three veins seen in Pal. 1242, here just one or two are visible. The surface appears to be smooth, at least on the part the proximal part of the wing anlagen is more wrinkly and difficult to distinguish from the other thoracic segments due to its poor preservation of details. Length of the wing anlage (WL in Fig. 4) is more than twice as long as the median line (L2 in Fig. 4).

The metathorax in dorsal view is partly concealed by the wing anlage of the mesothorax; only the more distal and the more proximal parts are visible. Venation of the wing anlage is slightly better preserved; two pronounced veins are apparent on the distal part and also indications of smaller veins on the proximal part, presumably parallel to the main veins. The length of the wing anlage of metathorax (WL in Fig. 4) is more than twice as long as the median line (L2 in Fig. 4), from what can be extrapolated from the visible parts.

The abdomen is more difficult to interpret than the thorax; the exact outlines of the tergites are not well preserved. The observable morphology resembles the one from Pal. 1242 in its overall shape; yet, there seem to be no 


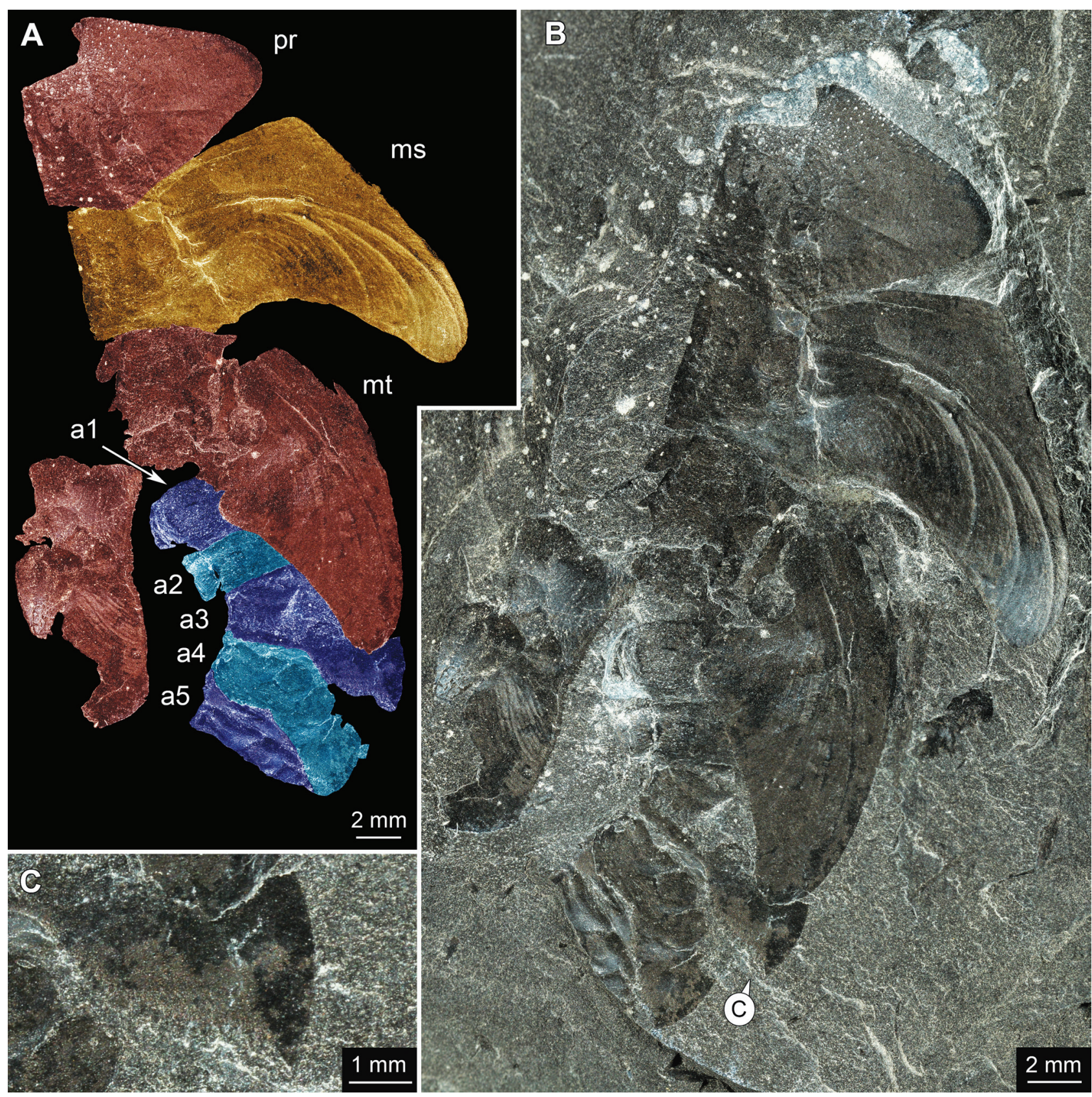

Figure 3. Rochdalia-type insect nymph from the Piesberg quarry. Counterpart of MaS Pal. 1242; A - colour marked version of B, colour-marking corresponding to Fig. 2B, overview image; C - close-up of first visible abdominal paranotal lobe of abdominal segment 3 (counterpart of Fig. 2C). Abbreviations as in Fig. 2.

pronounced paranotal lobes as seen in Pal. 1242, only (slight) indications; this may again be a preservation effect or due to its apparently changed orientational preservation.

The tergite of abdominal segment 1 (post-ocular segment 9) is more square shaped than the following abdominal segments and is partly covered by the metathoracic wing anlage. It also appears to have a different surface structure and colouration than all following segments, with similarities only to that of the wings. The tergite of abdominal segment 2 (post-ocular segment 10) has in opposite to the preceding segment a more widened, square-shape and a darker colouration. It also appears to have a more or less smooth surface, with a few wrinkles, perpendicular to the anteriorposterior axis. On the medio-anterior part of the tergite of abdominal segment 2 is a rectangular structure, which is set off from the rest of the segment (arrow Fig. 5A). On the more ventral side it has a few mostly circular white spots that congregate very lateral. These represent preparation artefacts. The segments are each about twice as wide as 


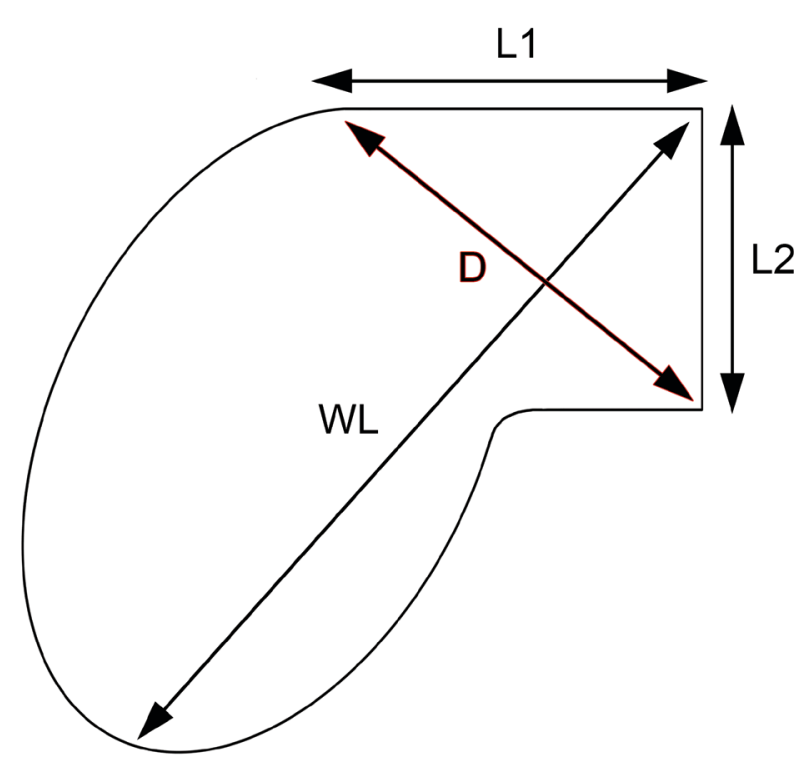

Figure 4. Measurement points along the wing. Schematic drawing. Abbreviations: D - diagonal of wing basis connecting outer ends of L1 and L2; L1 - anterior wing margin from median line to last abaxial point before wing bends posteriorly; L2 - median line as central line of notum; $\mathrm{WL}$ - wing length as measurement from most anterior point of the median line (L2) to wing apex.

long (absolute measurements for all abdominal segment measurements in Tab. 2), yet they are partly concealed by the wing anlagen, especially abdominal segment 2 which seems to probably have a paranotal lobe remain visible under the metathoracic wing anlage.

The tergites of abdominal segments 3-5 (post-ocular segments 11-13) deviate slightly from the squared to rectangular shape, as they have remains of presumably paranotal lobes that are roughly similar to that of abdominal segment 2. That makes them appear even wider than long, more like an elongated trapezoid than a rectangle. This is probably caused by the orientation of the specimens, which is different from that in Pal. 1242, as it presents a slightly more lateral view. The tergite of abdominal segment 3 (post-ocular segment 11) is three times as wide as long, the following two segments just twice as wide as long. This tergite shows a similar colouration to its preceding segment and even more wrinkles, but it lacks the set off rectangular structure of the tergite of abdominal segment 2 . There are also white, mostly circular spots of preparation artefacts on its paranotal lobe and also a few on the other side of the segment. The tergite of abdominal segment 4 (post-ocular segment 12) has, different from preceding segment, a darker colouration and the same set off structure of abdominal segment 2, though here it circular and more set off (arrow Fig. 5A). It has an overall smoother surface than its preceding segment. The tergite of abdominal segment 5 (post-ocular segment 13) looks overall more like abdominal segment 3 , in colouration and also without the set off structure and the overall surface structure, though it has white, mostly circular spots more ventral and on the paranotal lobes, as with abdominal segments 2 and 3 (preparation artefacts). The tergites of abdominal segments 6-9 (post-ocular segments 14-17) are more rectangular with no apparent paranotal lobes and an overall smooth surface save for the white spots of preparation artefacts. The tergite of abdominal segment 6 (post-ocular segment 14) is of the same colouration as the tergite of abdominal segment 4 , but it is covered with the white, circular preparation spot. It also has the circular, set off structure of the tergite of abdominal segment 4 and is also twice as wide as long. The tergite of abdominal segment 7 (post-ocular segment 15) is similar in all regards to its preceding segment, though it has slightly less preparation artefacts and appears to be also slightly smaller. It is less than twice as wide as long. The tergite of abdominal segment 8 (post-ocular segment 16) is of same colouration again, with also fewer preparation artefacts, but no set off structure. It is twice as wide as long. The tergite of abdominal segment 9 (post-ocular segment 17 ) has a slightly paler colouration. The then following structure is of comparable shape to that of Pal. 1242. Yet due to preservation there are no distinguishable sub-structures. The entire structure is as long as the four preceding abdominal segments combined or nearly four times as long as its base wide (absolute measurements in Tab. 2). Its surface appears to be overall smooth, without the few white preparation artefact spots that are on its more posterior part.

\section{Description of F246}

This specimen also represents the incomplete remains of a palaeodictyopteran nymph (Fig. 6). It is slightly smaller than the preceding two, but in general morphology resembles these specimens. Mainly differences are pointed out.

The head (ocular segment and post-ocular segments $1-5$ ), part of the thorax (pro- and mesothorax; post-ocular segments 6-7) and all thoracic legs are not visible, due to preservation. The metanotum is more completely preserved with its wing anlagen in dorsal view. Its shape is similar to that of Pal. 1242. Venation of the wing anlage is visible with the three (possible) major veins, but again not as well preserved as in Pal. 1242. There are indications of smaller veins, parallel to the three major veins. The surface structure of the metanotum is difficult to discern as it mostly appears smooth and otherwise follows the structures of the surrounding stone matrix. The colouration of the surface is homogeneous a paler grey than the surrounding matrix in the part (Fig. 6A); in the counterpart 


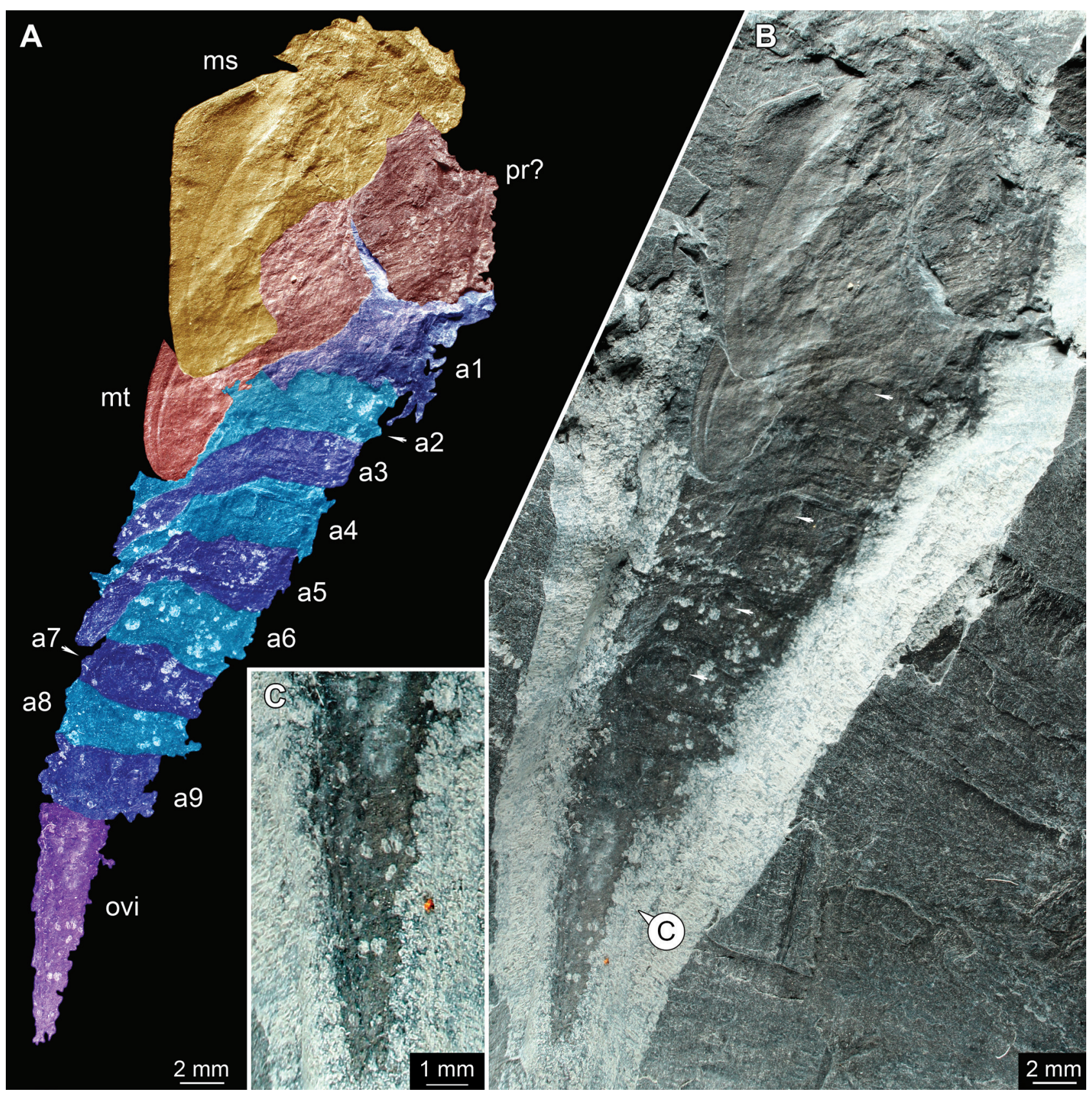

Figure 5. Rochdalia-type insect nymph from the Piesberg quarry, specimen F208; A - colour-marked version of B, colour-marking corresponding to Fig. 2B, overview image; arrows mark possible stigma openings; C - close-up of ovipositor. Abbreviations as in Fig. 2.

it is darker (Fig. 6D). The left wing anlage (Fig. 6A) seems to have a weak serration on its posterior edge, which also appears on the counterpart (Fig. 6D). Its wing anlagen length (WL in Fig. 4) is nearly three times as long as the median line (L2 in Fig. 4), as is also in Pal. 1242.

The abdominal segments are slightly wider than those of the other specimens (in dorsal view), but in general similar. The wider appearance can most likely be attributed to pronounced paranotal lobes. These have a more pronounced triangular to lobed shape. The paranotal lobes also appear to be stronger set off from the central part of the tergite. The tergites of the first two visible segments are twice as wide as long. The tergite of the following segment is thrice as wide as long. The presumable paranotal lobes preserved on the opposite side (see especially paranotal lobes of abdominal segment 6 and 7; right side in Fig. 6C) seem to be rather triangular and sharp in shape, but this might be a preservation artefact.

That has effects on the size as the tergites of the last three segments are three times as wide as long, which is 
relatively wider than in Pal. 1242. The overall surface of the tergites of the abdominal segments appears to be similar to that of the wing anlagen, smooth with structures indiscernible from the surrounding stone matrix. However, the surface colouration is more variable, as the last three segments are darker medially than on their edges. The posterior end is formed by an elongate triangular structure, which strongly resembles those of the other specimens in its shape, but is not too well preserved. Its surface structure is similar to that of the preceding abdominal segments, as is the colouration. It is darker on the left hand side (Fig. 6A) than on the other side, in a similar fashion as the tergites of the three preceding segments. It is more than three times as long as wide on its base. It has some saw-like serrations like Pal 1242.

\section{Description of F133, F134}

Specimens F133, F134 are remains of wing anlagen of presumably the same specimen, due to very close spatial association - F133 presumably represents a meso- and F134 a metathoracic wing anlage (Fig. 7A, B). The overall size of both wing anlagen appears slightly larger than those of Pal. 1242.

Specimen F133 shows several similarities to mesonotum of Pal. 1242, though on its base it is anteriorly incomplete. The sharp angle at which the wing bends posteriorly and the general shape is very similar to Pal. 1242. Its length (WL in Fig. 4) is nearly twice as long as the median line, so appears slightly shorter than in Pal. 1242. Yet, this might be due to preservation effects. The venation pattern of the wing anlagen is also nearly exactly the same as in Pal. 1242, beginning in the upper $2 / 3$ part of the median line and then bending towards the wing tip with three veins. Parallel to that are indications of other, smaller, veins. Its surface appears to be overall lightly granulated. The colouration of the surface is more or less homogeneous, with only a few paler patches on its anterior margin and on the tip.

Specimen F134 resembles a part of the metanotum of Pal. 1242, though again has more veins than are visible in Pal. 1242 with at least 5 different veins. It is slightly incomplete at its base and anteriorly near the wing tip, where the former broke off. Its length (WL in Fig. 4) is at least twice as long as the median line, so slightly shorter than in Pal. 1242. Again this might be due to preservation effects. The surface structure is also a little bit granular, and the colouration of the surface also mostly resembles that of F133. The anterior margin is more strongly coloured than the rest of the metanotum (F134) which is compared to the mesonotum (F133) slightly paler. Veins here are overall less detectable than in its mesonotum.

\section{Description of F136}

This represents presumably a mesothoracic fragment (Fig. 7C, D). It resembles the mesonotum of Pal. 1242 and F 134. This accounts for shape, the sharp angle at which it bends posteriorly (though slightly sharper than in Pal. 1242) and the pronounced venation of the wing anlagen with the three main veins and possibly other veins. There are indications of paralleling smaller veins. It is nearly a complete wing anlage, though near the base of the wing anlage it is slightly incomplete. Its length (WL in Fig. 4) is at least 2.5 times as long as the median line (L2 in Fig. 4) like it is in Pal. 1242 approximately. The size is most similar to the one of F 133. Its surface structure appears, especially at its base, very wrinkly at some parts and at others more smooth. The colouration is not homogeneous, as it has darker patches on the tip of the wing anlagen, the lateral margin at its base and on the three main veins.

\section{Description of Pal. 709}

This represents presumably a mesothoracic fragment (Fig. 7E, F), which seems also most similar to that of Pal. 1242. This accounts for general shape, the sharp angle at which it bends posteriorly and the more or less pronounced venation of the wing anlage with the three main veins. There are also indications of paralleling smaller veins. This wing anlage seems to be more complete at its base than F133, but there is instead some part posteriorly in the middle of the wing anlage missing. Its length (WL in Fig. 4) is at least twice as long as the median line (L2 in Fig. 4), so slightly shorter than in Pal. 1242. Also this might be due to preservation effects. The overall size is quite similar to the mesonotum of Pal 1242.

Its surface appears more or less smooth with a little bit of granulation, and the colouration of the surface is, again, homogeneous with the exception of the tip of the wing anlage where it is of a paler colour with dark patches.

\section{Discussion}

\section{Systematic interpretation}

One can interpret the here described specimens as possibly conspecific (see also further below) and we discuss their affinities therefore together. The overall insect affinity of these fossils should be clear due to the principle tagmosis (body organisation) of the more complete specimens.

The morphology of these specimens is furthermore characterised by: 1) pronounced paranotal lobes on the pronotum and a concave anterior rim of the latter, 2) 



Figure 6. Rochdalia-type insect nymph from the Piesberg quarry, specimen F246; A - overview image of F246; B - colour-marked version of A, colour-marking corresponding to Fig. 2; C - colour-marked version of A; D - overview image of counterpart to A; E - close-up of ovipositor from A; F - close-up of ovipositor from D. Abbreviations as in Fig. 2.

pronounced wing anlagen on mesonotum and metanotum with apparent, but simple venation and 3) paranotal lobes arising from abdominal segments that do not show the more feathery appearance of gills.

Paranotal lobes on the pronotum are most likely a plesiomorphy for all pterygotes, and became repeatedly lost in different lineages (compare Kukalová-Peck 1978, Rasnitsyn 1981). Also pronounced wing anlagen are most likely an ancestral feature that was reduced repeatedly in several lineages (recent review in Haug et al. 2016), but make it most likely that the specimens represent nymphal stages (they could more unlikely represent paedomorphic forms, see discussion in Hörnig et al. 2018). Abdominal paranotal lobes might also be plesiomorphic (see examples in Prokop et al. 2016b) but seem to be not too common. In ephemeropterans such abdominal paranotal lobes are developed as gills (see discussions in Grimaldi \& Engel 2005 or Tomoyasu et al. 2017), which is not the case here. Hence the specimens are characterised by numerous presumably plesiomorphic features. A candidate group 
for insects with numerous plesiomorphies is the group Palaeodictyopteroidea, a now extinct group of insects with piercing mouth parts.

There are currently (roughly) three major types of Carboniferous insect nymphs apart from those that can directly be identified as dictyopteran nymphs, among them palaeodictyopteran-type nymphs, which can be compared to the specimens at hand:

1) Lameereites-type nymphs (Haug et al. 2016) show the least similarities to the here described specimens. The paranotal lobes of the pronotum are almost absent, thin spines may represent remains of it (Kukalová-Peck 1972). The wing anlagen are curved and lobe-like and appear less rigid. Finally the abdomen is slender and elongate, distantly resembling that of modern adult dragonflies.

2) Herdina-type nymphs (Haug et al. 2016) are more similar to the specimens described here. Paranotal lobes of the pronotum are present, but not as pronounced; also no anterior concavity of the pronotum is apparent. The wing anlagen are also less rigid and possess a pronounced mesh-like vein pattern as opposed to the curved veins in the specimens described here. Lastly, while the abdomen appears quite wide, most likely due to abdominal paranotal lobes, these do not appear to be as pronounced as in the here described material.

3) Rochdalia-type nymphs are extremely similar to the here described material in all aspects, pronotum, wing anlagen and abdomen morphology. The here described specimens show a very close resemblance to a palaeodictyopteran insect nymph described by Rolfe (1967) and Wootton (1972) under the name Rochdalia parkeri as well as similar looking Idoptilus onisciformis. These two supposed species possibly represent nothing less than two stages of an ontogenetic sequence (see further below for details; see also Prokop et al. 2017b for recent investigation on these specimens).

The thoracic tergites appear largely indistinguishable; the abdominal segments at least in the best preserved specimens (Pal. 1242) differ slightly more from the nymphs described by Rolfe (1967). In the new specimens the paranotal lobes are more pronounced and have sawlike serrations posteriorly though the overall tapering shape (towards posterior) seems to be very similar. This difference might be explained by a) better preservation of the new specimen or b) the fact that these specimens represent two different species that differ in this respect.

A new character not described before on this type of nymph is the elongate, massive, triangular and tripartite structure at the posterior body end. It can be interpreted in the following way: the entire triangular structure presumably represents the ovipositor, with three structures as possibly three valves; further valves are most likely not visible due to preservation; i.e. most likely covered by the observable ones. Rolfe (1967) and Wootton (1972) described two specimens, without comparable structures preserved. The here described specimens are hence extremely similar to the nymphs described by Rolfe (1967) and Wootton (1972). We therefore interpret the here described specimens as Rochdalia-type palaeodictyopteran nymphs.

\section{Similarities to dictyopteran nymphs}

While most authors interpret Rochdalia-type nymphs as nymphs of palaeodictyopterans, there still seems to be a resemblance with roachoid ones (i.e. early representatives of Dictyoptera sensu lato sensu Hörnig et al. 2018). Rolfe (1967) e.g. depicts a third nymph strongly resembling the Rochdalia-type ones, but being interpreted as a roach-like nymph hence a dictyopteran. The specimen was recently reinterpreted as a species of Idoptilus (Prokop et al. 2018). Dictyopteran nymphs indeed show numerous similarities with palaeodictyopteroidean nymphs. This is in fact a major problem especially when a fossil specimen is fragmentary - which seems to be the most common preservation. The standard criteria to distinguish fragmentary insects especially wing venation pattern is challenging to apply, as in nymphal stages venation of wing anlagen is less pronounced and less complex. If not found together with the more complete specimens the tergite fragments described here could have been as well interpreted as remains of dictyopterans, which are known to have occurred in the Piesberg-quarry fauna (Haug et al. 2013, Hörnig et al. 2014).

The overall habitus is at first glance similar in nymphal dictyopterans and Rochdalia-type nymphs. Differences include:

1) The shape of the pronotum which appears more rounded in co-occurring dictyopterans (sensu lato) (Hörnig et al. 2014), but more polygonal and anteriorly notched in Rochdalia-type nymphs.

2) It seems also that the mesothoracic wing anlagen is bending with a slightly sharper posteriorly angle in fossil dictyopterans than Rochdalia-type-nymphs.

3) The surface of the mesonotum anterior to the veins appears tuberculate in the new Rochdalia-type specimens. Dictyopterans seem to have a smooth surface in this area.

Many other aspects are quite similar. Also dictyopteran nymphs can possess quite well-developed wing anlagen, as well as abdominal paranotal lobes. Yet, all these similarities cannot be easily used to argue for a closer relationship between the two. When comparing these characters in a wider scale it seems most likely that all these characters represent symplesiomorphies retained in Rochdalia-type nymphs, as well as in dictyopteran-type 

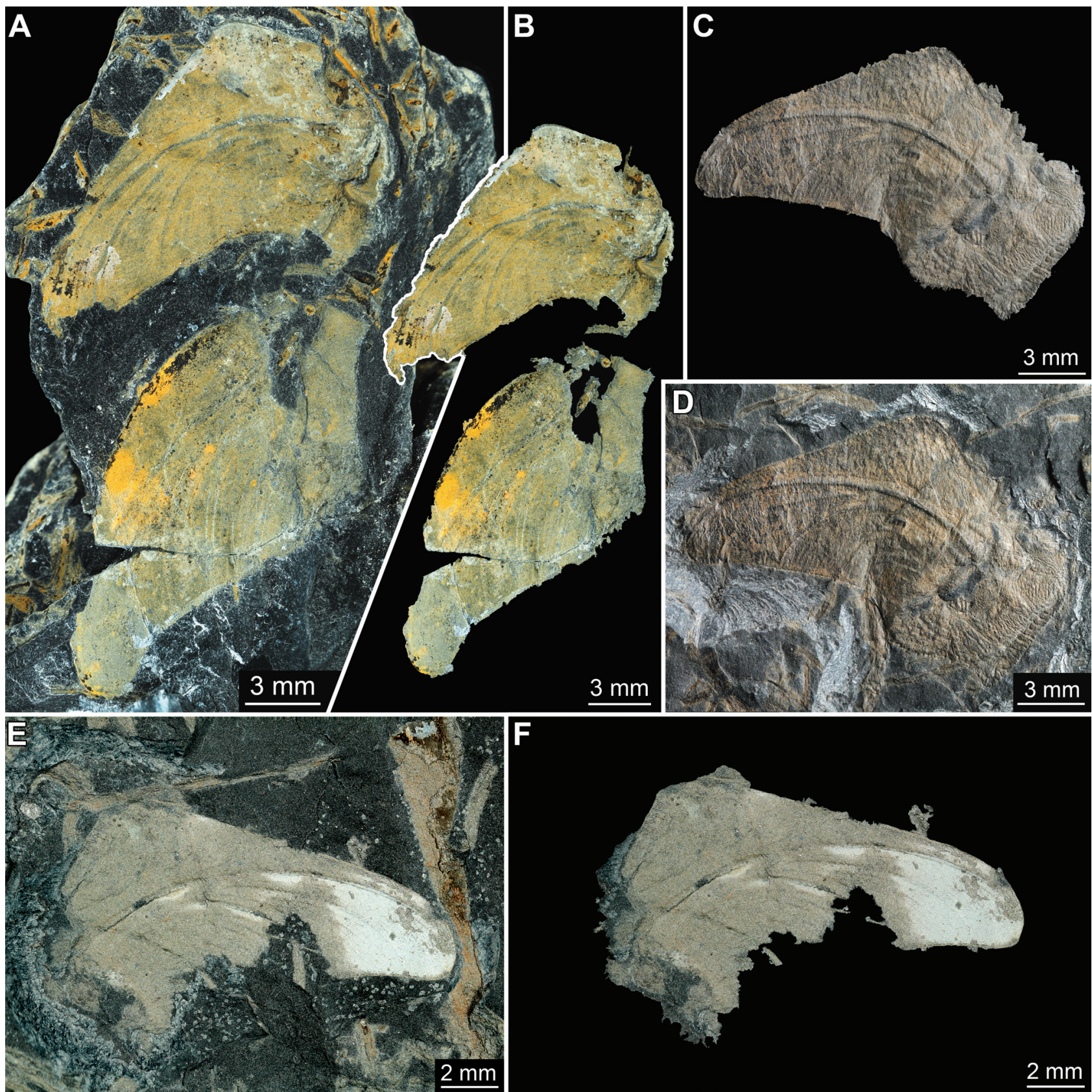

Figure 7. Rochdalia-type insect nymphal wing fragments from the Piesberg quarry. Specimens F133, F134, F136, Pal. 709; A, B - overview of F133 (mesothoracic wing; upper one) and F134 (metathoracic wing; lower one); C, D - overview of F136 (mesothoracic wing); E, F - overview of Pal. 709 (mesothoracic wing).

nymphs. This indicates that among the three types of presumed palaeodictyopteroidean nymphs the Rochdaliatype is possibly the least derived one and hence important for the understanding of the ontogeny in early insects.

\section{Conspecifity and ontogenetic sequence}

All three more complete specimens (F208, F246, Pal. 1242; Figs 2, 3,6) strongly resemble each other. There are no characters apparent that could be attributed to species differences. All recognisable differences are either preservational or could be ontogenetic. Specimen F 208 is significantly smaller and hence most likely represents an earlier developmental stage. The fragmentary tergites described here (F133, F134, Pal. 709 and F136; Fig. 7) show the exact same morphology as those on the more complete specimens, with the general outline, the characteristic posteriorly bending angle of the apex and the few veins of the wing anlagen. Specimen Pal. 709 
matches exactly with the mesonota of the more complete specimens and hence most likely represents the same developmental stage. Specimens F133, F134 and F136 are larger, but otherwise show the exact same outline, hence most likely represent a later developmental stage.

There are not too many morphological differences observable that could be interpreted as changes throughout a presumed ontogenetic sequence. The smallest specimen (F246) shows a venation of the wing anlage that is less pronounced than in the others, which could be attributed to a less far developed status. Also the fact that in F133, F134 more veins are pronounced could be explained by an ontogenetic sequence.

One can also not fully exclude that the three presumed stages represent the corresponding stages of three different sized species. Yet, this may not be parsimonious and also does not explain the less pronounced venation of the wing anlagen in the smallest specimen. Hence following Ockham's razor the material described here is interpreted as representing an ontogenetic sequence of three stages of a single species. One can currently not suggest how the adult might have looked like, besides the fact that the female should have possessed a massive ovipositor and paranotal lobes.

\section{Taxonomy}

While there remain many uncertainties, we provide, based on the discussion above, a taxonomic interpretation:

Insecta Linnaeus, 1758

Pterygota Gegenbaur, 1878

Palaeoptera Martynov, 1923

Palaeodictyopteroidea Rohdendorf, 1961

\section{Incertae sedis}

Remarks. - Although it is in principle possible to identify immature insects to species, this is not possible in the current case. Also, immature insects have been used to erect new species. Also this is in principle possible when providing a differential diagnosis. As adult palaeodictyopteroideans are known from the same deposit, a conspecifity to the nymphs cannot be easily excluded. Hence we refrain of erecting a new species on the specimens in order to not create synonyms.

\section{Ontogenetic sequence: extrapolated}

While it is difficult to infer ontogenetic morphological changes based on the present material, one can make some rough extrapolations when including the known specimens of the Rochdalia-type (Rolfe 1967, Wootton 1972) into the discussion. As these are very unlikely to be conspecific, any inferences become "more blurry" as the species from the UK (Rolfe 1967, Wootton 1972) might possess slightly different developmental patterns to that from Germany. Nevertheless such coarser ontogenetic reconstructions have been employed e.g. for megasecopterans (recent review Haug et al. 2016) and still provided interesting insights. In the current case one can state the following:

The smaller specimen of the Rochdalia-type (shown as combined with here described details in Fig. 8A) from the UK has less pronounced venation of the wing anlagen and its lateral wing anlagen rim are almost parallel to the body axis diverging only about $12^{\circ}$ (Fig. $8 \mathrm{D}$ ). This could correspond well to the developmental state of F246.

The larger specimen of Rochdalia (also shown as combined with here described details in Fig. 8A, B) has slightly longer wing anlagen which show more veins. The lateral edge forms an angle of about $18^{\circ}$ against the body axis (Fig. 8E).

In the larger specimens (here described) the wing anlagen are even more pronounced, longer with more veins indicated (Fig. 8C). The angle against the body axis has reached $30^{\circ}$ (Fig. 8F).

This provides a plausible reconstruction of the ontogeny of Rochdalia-type insects. The overall ontogeny is very gradual. The wing anlagen are at first directed more posteriorly but successively are held more laterally (Fig. 8) as known for megasecopterans, i.e. Lameereites-type nymphs (but see Prokop et al. 2017a). The gradualness of the sequence is further emphasised by the presence of a massive ovipositor, a typical adult feature. This also demonstrates that the two specimens from the UK, although generally recognised as two species might well represent nothing less than two stages of one species. At least it becomes more difficult to provide a clear differential diagnosis for them as differences between them seem to correspond to ontogenetic differences.

\section{Ovipositor: identity}

The posterior triangular, elongated structure shown by all three more complete specimens (Figs 2D; 5C; 6E, F) is interpreted as the ovipositor. Best preservation is seen in Pal. 1242 (Fig. 2); here the supposed ovipositor is even subdivided into three parts, most likely representing valves (Fig. 2D).

Based on the posterior position one could also argue that this structure could be alternatively interpreted. For example it could be suggested that these represent unusually preserved cerci. The shape would be rather uncommon, even if suggesting that the two cerci form 


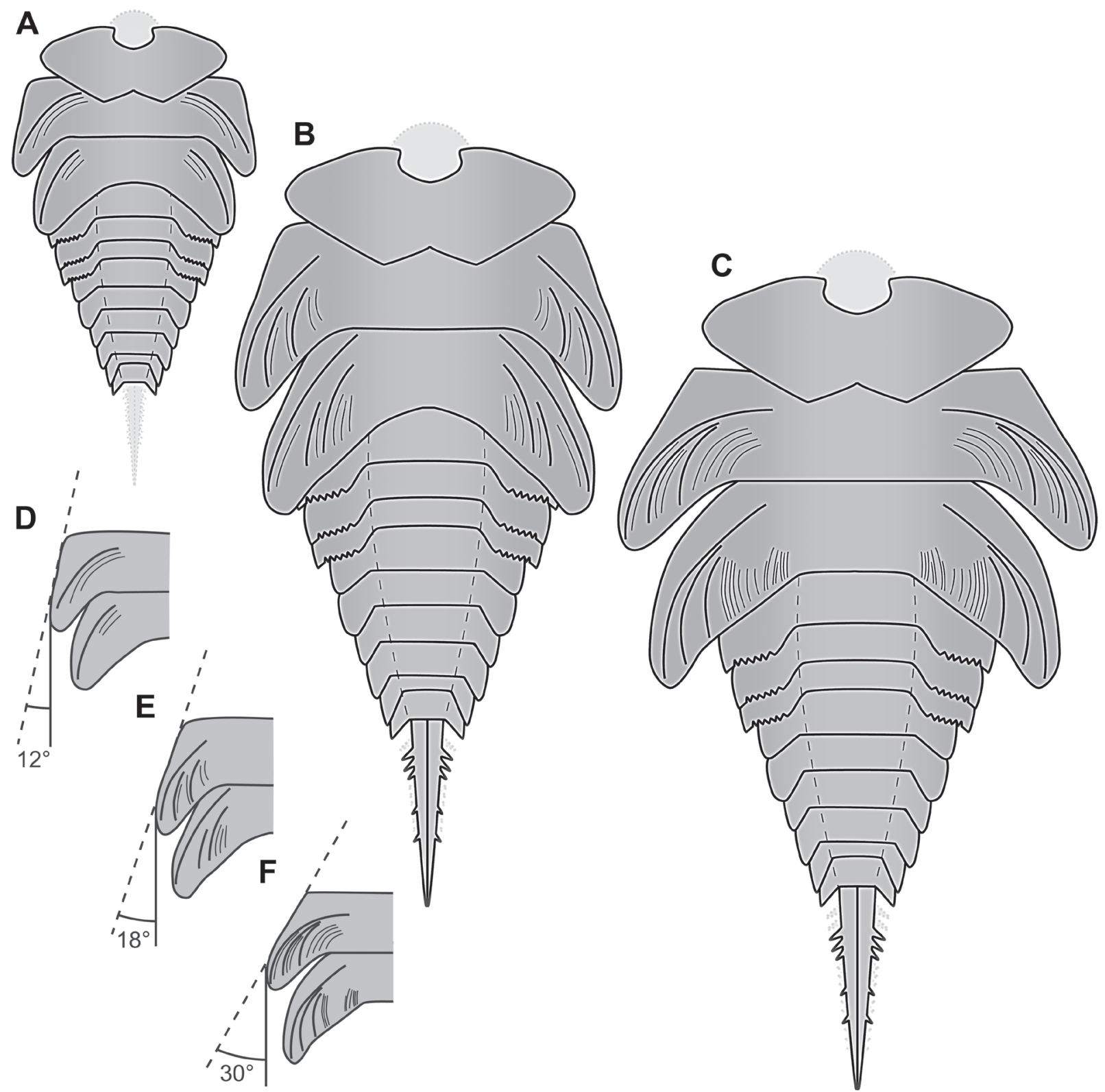

Figure 8. Simplified reconstruction of palaeodictyopteran nymphs in sequence; A, B - extrapolations based on Rolfe (1967) and Wootton's (1972) specimens; C - based on Pal. 1242; D-F - angles at which A-C's mesonotal wing anlagen bend backwards.

a triangular shape or sticking together as preservation effects. One should expect to see at least indications of annular structures. Also the serrations at its lateral parts are not easily compatible with the interpretation as cerci. The entire specimen is comparably well preserved, hence a preservational interpretation of these structures is not convincing.

In extant dragonfly nymphs the paraprocts (elongations of ventral sclerotisations of the $11^{\text {th }}$ abdominal segment bordering the anus) seem to form a triangular shape (Fig. 9), hence one could argue that one faces a similar case in the described fossils. In the specimens at hand distinct abdominal segments 10 and 11 are not apparent, yet this accounts for most flying insects, not excluding these structures from arising from these segments.

More important, enlarged paraprocts seem to be restricted to odonatan type larvae and so far unknown in other early flying insects, still we cannot exclude that the structures seen here have evolved independently from odonatans.

The shape of the structures is more compatible with an interpretation as an ovipositor, as they are significantly more elongated than paraprocts of odonatan larvae. Still one has to admit that the structure is also wider at its base than most ovipositors. 
An important argument for an interpretation as an ovipositor is the lateral serrations of the structures. Such serrations are known from extant ovipositors in groups such as Odonata (see also further below).

Finally, we know that late nymphal stages indeed can possess rather prominent ovipositor precursors (see Hörnig et al. 2018 for a recent summary). One example is nymphs of the fossil odonatan group Aeschnidiidae, which bear very long ovipositors (e.g. Zhang 1999, 2000; Zhang \& Zhang 2001). Also among palaeodictyopteran nymphs well-developed ovipositor structures can occur, but the exact length cannot be inferred due to fragmentary preservation (Prokop et al. 2016b). Taken together we prefer the interpretation of the structure as an ovipositor over alternative interpretations based on the criterium of Ockham's razor.

\section{Ovipositor: biological interpretation}

Why do these - probably late, but still - nymphs have such prominent, 'normally' adult characteristics as a pronounced ovipositor? This may be explained by a "construction limitation". Massive ovipositors in the nymph can be interpreted as an indication for an even larger ovipositor in the adult. Such a massive ovipositor presumably needs to be 'built-up' step wise in a gradual manner. Similar cases are known in some groups of extant orthopterans and fossil representatives of Dictyoptera sensu lato (Hörnig et al. 2018).

Such massive ovipositors are most probably used for endophytous egg-laying. In such cases a large, pointed structure is required to breach a plant's outer cell layer to create a cavity for the eggs. The serrations as seen in Pal. 1242 (Fig. 2D) have most likely supported this process by sharpening the edges (in a saw-like manner) and making it easier for creating that cavity inside the plants.

Finally one can even speculate that the large sized ovipositor gives us further hints about the breeding biology. One should expect a correlation between ovipositor size and egg size, at least to a certain degree. Hence, such a massive ovipositor is most likely indicative of large and yolk-rich eggs. Ovipositors of other palaeodictyopteroideans are also large, but not as massive. These resemble the curved and more slender ovipositors seen in orthopterans (Kukalová 1969b, Kukalová-Peck 1971). There are also palaeodictyopteroideans with straight ovipositors (e.g., Prokop et al. 2016a), but which are not as long as those described in this study, not significantly extending beyond the posterior body end.

\section{Conclusion}

Here a first selection of nymphal palaeodictyopterans found in the Piesberg quarry is presented. Especially their

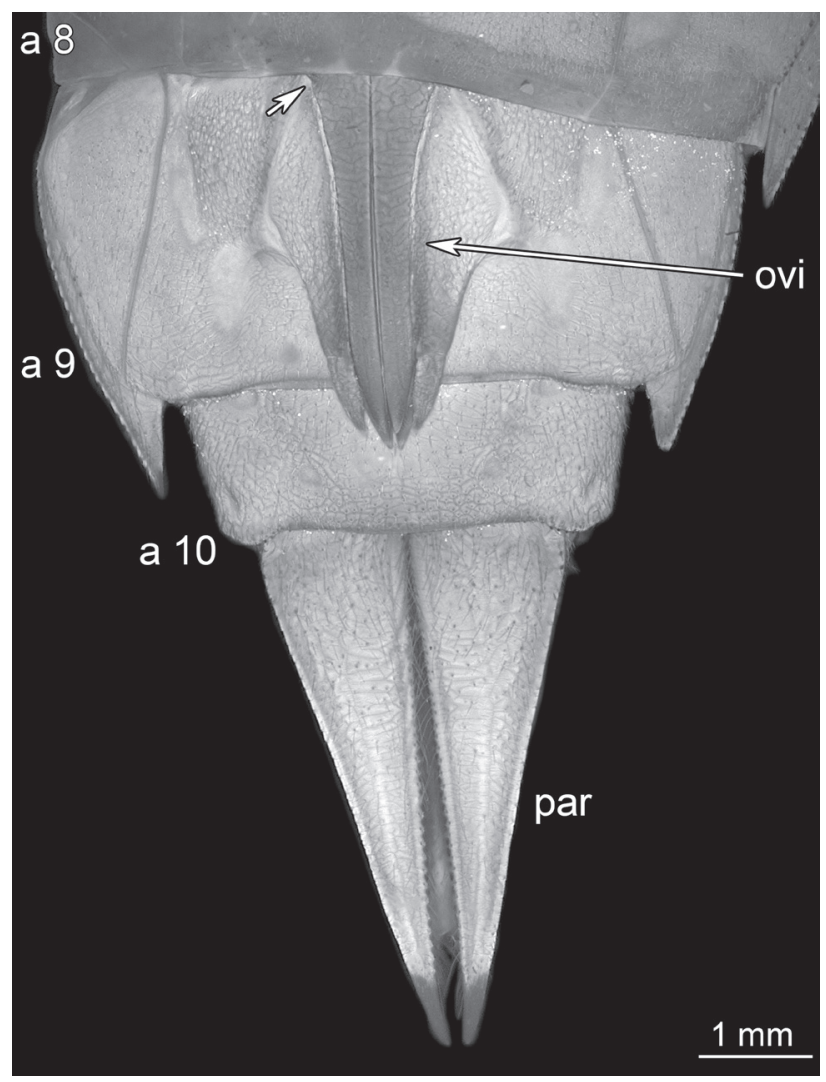

Figure 9. Posterior of abdomen from an extant dragonfly nymph. Arrow indicates that the ovipositor rises from abdominal segments 8 and 9. Abbreviations: a - abdominal segment; ovi - ovipositor; par paraprocts.

combination of far developed presumed genital structures and still underdeveloped wings is interesting, giving important insights into the developmental biology of this extinct insect group. Comparable fossils still represent something rare with few finds so far worldwide. The Piesberg quarry has demonstrated in recent years that its fossils provide significant new insights into the ontogeny of Moscovian aged, 308 million years old arthropods (Haug et al. 2012, 2013; Nel et al. 2013; Hörnig et al. 2014) and the new finding add to this list. One can expect further important findings from the Piesberg quarry in the future.

\section{Acknowledgements}

We would like to thank André Nel, Paris, and an anonymous reviewer for helpful comments. Special thanks also to J. Matthias Starck for his support. We would also like to thank the pro bono collectors Michael Sowiak, Glandorf and Stephan Brauner, National GeoPark Thuringia at the Piesberg quarry for finding the specimens described herein and the CEMEX-Company at the Piesberg quarry for allowing the collectors to search at the Piesberg quarry. JTH was kindly funded by German Research Council (DFG; Funding number: HA 6300/3-1), and is currently kindly funded by the Volkswagen 
Foundation in the frame of a Lichtenberg Professorship. The Bavarian Equal Opportunities sponsorship (BGF) of the LMU kindly funded $\mathrm{CH}$. MKH was kindly funded by the Studienstiftung des deutschen Volkes. This study benefited heavily from the free software Combine ZP. We therefore thank all the people involved in programming such software.

\section{References}

Béthoux, O., Voigt, S. \& Schneider, J.W. 2010. A Triassic palaeodictyopteran from Kyrgyzstan. Palaeodiversity 3, 9-13.

Brauckmann, C. 1991. Morphologie und Variabilität von Homoioptera vorhallensis (Insecta: Palaeodictyoptera; OberKarbon). Geologica et Palaeontologica 25, 193-213.

Brauckmann, C. 1995. Neue Insekten-Funde (Palaeodictyoptera: Breyeriidae) aus dem Ober-Karbon von Osnabrück (Deutschland). Osnabrücker Naturwissenschaftliche Mitteilungen 20, 157-165.

Brauckmann, C. \& Hahn, G. 1978. Ein neuer PalaeodictyopterenFund aus dem westdeutschen Namurium. Paläontologische Zeitschrift 52, 13-18. DOI 10.1007/BF03006726

Brauckmann, C. \& Herd, K.J. 2002. Insekten-Funde aus dem Westfalium D (Ober-Karbon) des Piesberges bei Osnabrück (Deutschland). Teil 1: Palaeoptera. Osnabrücker Naturwissenschaftliche Mitteilungen 28, 27-69.

Brauckmann, C., Herd, K.J. \& Leipner, A. 2009. InsektenFunde aus dem Westfalium D (Ober-Karbon) des Piesberges bei Osnabrück (Deutschland). Osnabrücker Naturwissenschaftliche Mitteilungen 35, 1-30.

Carpenter, F.M. 1948. The supposed nymphs of the Palaeodictyoptera. Psyche: A Journal of Entomology 55, 41-50. DOI 10.1155/1948/83246

Carpenter, F.M. 1992. Superclass Hexapoda, 1-665. In KAESLER, R.L. (ed.) Treatise on Invertebrate Paleontology: Pt. R, Arthropoda 4. Geological Society of America \& University of Kansas Press, Boulder \& Lawrence.

CArpenter, F.M. \& Burnham, L. 1985. The geological record of insects. Annual Review of Earth and Planetary Sciences 13, 297-314. DOI 10.1146/annurev.ea.13.050185.001501

Dunlop, J.A., Brauckmann, C. \& Steur, H. 2008. A Late Carboniferous fossil scorpion from the Piesberg, near Osnabrück, Germany. Fossil Record 11, 25-32.

DOI 10.1002/mmng.200700010

Gegenbaur, C. 1878. Grundriss der vergleichenden Anatomie. $655 \mathrm{pp}$. Verlag von Wilhelm Engelmann, Leipzig. DOI 10.5962/bhl.title.2157

Grimaldi, D. \& Engel, M.S. 2005. Evolution of the Insects. 755 pp. Cambridge University Press, Cambridge.

Haug, C., Haug, J.T., Waloszek, D., Maas, A., Frattigiani, R. \& Liebau, S. 2009. New methods to document fossils from lithographic limestones of southern Germany and Lebanon. Palaeontologia Electronica 12, 6T.

Haug, C., Mayer, G., Kutschera, V., Waloszek, D., Maas, A. \& HAUG, J.T. 2011. Imaging and documenting gammarideans. International Journal of Zoology, art. 380829. DOI 10.1155/2011/380829

Haug, C., Van Roy, P., Leipner, A., Funch, P., Rudkin, D.M.,
SchöllmanN, L. \& Haug, J.T. 2012. A holomorph approach to xiphosuran evolution - a case study on the ontogeny of Euproops. Development Genes and Evolution 222, 253-268. DOI 10.1007/s00427-012-0407-7

Haug, J.T., Haug, C. \& Ehrlich, M. 2008. First fossil stomatopod larva (Arthropoda: Crustacea) and a new way of documenting Solnhofen fossils (Upper Jurassic, Southern Germany). Palaeodiversity 1, 103-109.

Haug, J.T., Haug, C. \& Garwood, R. 2016. Evolution of insect wings and development - new details from Palaeozoic nymphs. Biological Reviews 91, 53-69.

DOI 10.1111/brv.12159

Haug, J.T., Leipner, A., Wappler, T. \& Haug, C. 2013. Palaeozoic insect nymphs: new finds from the Piesberg quarry (Upper Carboniferous, Germany). Bulletin of Geosciences 88, 779-791. DOI 10.3140/bull.geosci.1401

Hörnig, M.K., Haug, C., Herd, K.J. \& Haug, J.T. 2014. New insights into dictyopteran early development: smallest Palaeozoic roachoid nymph found so far. Palaeodiversity 7, 159-165.

Hörnig, M.K., Haug, C., Schneider, J.W. \& Haug, J.T. 2018. Evolution of reproductive strategies in dictyopteran insects clues from ovipositor morphology of extinct roachoids. Acta Palaeontologica Polonica 63, 1-24.

DOI 10.4202/app.00324.2016

Josten, K.H., Köwing, K. \& Rabitz, A. 1984. Oberkarbon, 7-77. In Klassen, H. (ed.) Geologie des Osnabrücker Berglandes. Naturwissenschaftliches Museum, Osnabrück.

Kerp, H. \& Bomfleur, B. 2011. Photography of plant fossils new techniques, old tricks. Review of Palaeobotany and Palynology 166, 117-151. DOI 10.1016/j.revpalbo.2011.05.001

KukalovÁ, J. 1969a. Revisional study of the order Palaeodictyoptera in the Upper Carboniferous shales of Commentry, France. Part I. Psyche: A Journal of Entomology 76, 163-215. DOI 10.1155/1969/74019

Kukalová, J. 1969b. Revisional study of the order Palaeodictyoptera in the Upper Carboniferous shales of Commentry, France. Part II. Psyche: A Journal of Entomology 76, 439-486. DOI 10.1155/1969/20732

Kukalová, J. 1970. Revisional study of the order Palaeodictyoptera in the Upper Carboniferous shales of Commentry, France. Part III. Psyche: A Journal of Entomology 77, 1-44. DOI 10.1155/1970/71691

KukalovÁ-Peck, J. 1971. The structure of Dunbaria (Palaeodictyoptera). Psyche: A Journal of Entomology 78, 306-318. DOI 10.1155/1971/84672

KukalovÁ-Peck, J. 1972. Unusual structures in the Paleozoic insect orders Megasecoptera and Palaeodictyoptera, with a description of a new family. Psyche: A Journal of Entomology 79, 243-268. DOI 10.1155/1972/98019

KuKalovÁ-Peck, J. 1978. Origin and evolution of insect wings and their relation to metamorphosis, as documented by the fossil record. Journal of Morphology 156, 53-125. DOI 10.1002/jmor.1051560104

Kukalová-Peck, J. \& Peck, S.B. 1976. Adult and Immature Calvertiellidae (Insecta: Palaeodictyoptera) from the Upper Paleozoic of New Mexico and Czechoslovakia. Psyche: A Journal of Entomology 83, 79-93. DOI 10.1155/1976/36962

Labandeira, C.C. \& Phillips, T.L. 1996. Insect fluid-feeding 
on Upper Pennsylvanian tree ferns (Palaeodictyoptera, Marattiales) and the early history of the piercing-and-sucking functional feeding group. Annals of the Entomological Society of America 89, 157-183. DOI 10.1093/aesa/89.2.157

Labandeira, C.C., Beall, B.S. \& Hueber, F.M. 1988. Early insect diversification: evidence from a Lower Devonian bristletail from Québec. Science 242, 913-916.

DOI 10.1126/science.242.4880.913

Linnaeus, C. 1758. Systema naturae per regna tria naturae, secundum classes, ordines, genera, species, cum characteribus, differentiis, synonymis, locis. 824 pp. Stockholm, Laurentius Salvius.

Martynov, A.V. 1923. On two basic types of insect wings and their significance for the general classification of insects, 88-89. In Deryugina, K.M. (ed.) Trudy Pervogo Vserossijskogo S'ezda Zoologov, Anatomov $i$ Gistologov 1.

Nel, A., Roques, P., Nel, P., Prokin, A.A., Bourgoin, T., Prokop, J., Szwedo, J., Azar, D., Desutter-Grandcolas, L., Wappler, T., Garrouste, R., Coty, D., Huang, D., Engel, M.S. \& KIREJTSHUK, A.G. 2013. The earliest known holometabolous insects. Nature 503, 257-261. DOI 10.1038/nature12629

Pecharová, M., Ren, D. \& Prokop, J. 2015. A new palaeodictyopteroid (Megasecoptera: Brodiopteridae) from the Early Pennsylvanian of northern China reveals unique morphological traits and intra-specific variability. Alcheringa: An Australasian Journal of Palaeontology 39, 236-249. DOI 10.1080/03115518.2015.993299

Prokop, J. \& ReN, D. 2007. New significant fossil insects from the Upper Carboniferous of Ningxia in northern China (Palaeodictyoptera, Archaeorthoptera). European Journal of Entomology 104, 267-275. DOI 10.14411/eje.2007.041

Prokop, J., Pecharová, M., \& Ren, D. 2016a. Hidden surface microstructures on Carboniferous insect Brodioptera sinensis (Megasecoptera) enlighten functional morphology and sensorial perception. Scientific Reports 6, 28316. DOI 10.1038/srep28316

Prokop, J., Nel, A., Engel, M. S., Pecharova, M., \& HörnSCHEMEYer, T. 2016b. New Carboniferous fossils of Spilapteridae enlighten postembryonic wing development in Palaeodictyoptera. Systematic Entomology 41, 178-190. DOI 10.1111/syen. 12148

Prokop, J., Pecharová, M., Jarzembowski, E.A. \& Ross, A.J. 2018. New palaeodictyopterans from the Late Carboniferous of the UK (Insecta: Palaeodictyopterida). Earth and Environmental Science Transactions of the Royal Society of Edinburgh 107, 99-107. DOI 10.1017/S1755691017000408

Prokop, J., Pecharová, M., Nel, A., Grey, M. \& Hörnschemeyer, T. 2017a. A remarkable insect from the Pennsylvanian of the Joggins Formation in Nova Scotia, Canada: insights into unusual venation of Brodiidae and nymphs of Megasecoptera. Journal of Systematic Palaeontology 15, 1051-1065. DOI 10.1080/14772019.2017.1283364

Prokop, J., Pecharová, M., Nel, A., Hörnschemeyer, T., KrzeMiŃSKA, E., KrzemiŃski, W. \& Engel, M.S. 2017b. Paleozoic nymphal wing pads support dual model of insect wing origins. Current Biology 27, 263-269.

DOI 10.1016/j.cub.2016.11.021
Prokop, J., TippeltovÁ, Z., Roques, P. \& Nel, A. 2013. A new genus and species of Breyeriidae and wings of immature stages from the Upper Carboniferous, Nord-Pas-de-Calais, France (Insecta: Palaeodictyoptera). Insect Systematics \& Evolution 44, 117-128. DOI 10.1163/1876312X-44032098

RASNITSYN, A.P. 1981. A modified paranotal theory of insect wing origin. Journal of Morphology 168, 331-338. DOI 10.1002/jmor.1051680309

Rasnitsyn, A.P. \& Quicke, D.L. 2002. History of insects. 517 pp. Kluwer Academic Publishers, Dordrecht. DOI 10.1007/0-306-47577-4

Richardson, E.S. 1956. Pennsylvanian invertebrates of the Mazon Creek area, Illinois. Insects. Fieldiana Geology 12, 15-56.

Rohdendorf, B.B. 1961. Podklass Pterygota [Subclass Pterygota], 69-88. In Rohdendorf, B.B., Becker-Migdisova, E.E., Martynova, O.M. \& Sharov, A. (eds) Paleozojskie nasekomye kuznetskogo bassejna [Palaeozoic insects of the Kuznetsk Basin]. Trudy Paleontologicheskogo Instituta Akademii nauk SSSR 85.

RoLfe, W.D.I. 1967. Rochdalia, a Carboniferous insect nymph. Palaeontology 10, 307-313.

Ross, A.J. 2010. A review of the Carboniferous fossil insects from Scotland. Scottish Journal of Geology 46, 157-168. DOI 10.1144/0036-9276/01-413

ShCHERBAKOv, D.E. 2011. The alleged Triassic palaeodictyopteran is a member of Titanoptera. Zootaxa 3044, 65-68. DOI 10.11646/zootaxa.3044.1.4

Sroka, P., Staniczek, A.H. \& Bechly, G. 2015. Revision of the giant pterygote insect Bojophlebia prokopi KukalováPeck, 1985 (Hydropalaeoptera: Bojophlebiidae) from the Carboniferous of the Czech Republic, with the first cladistic analysis of fossil palaeopterous insects. Journal of Systematic Palaeontology 13, 963-982.

DOI 10.1080/14772019.2014.987958

Tomoyasu, Y., Ohde, T. \& Clark-Hachtel, C. 2017. What serial homologs can tell us about the origin of insect wings. F1000Research, 6. DOI 10.12688/f1000research.10285.1

Wootton, R.J. 1972. Nymphs of Palaeodictyoptera (Insecta) from the Westphalian of England. Palaeontology 15, 662-675.

Wootton, R.J. 1981. Palaeozoic insects. Annual Review of Entomology 26, 319-344.

Wootton, R.J. \& KuKalovÁ-Peck, J. 2000. Flight adaptations in Palaeozoic Palaeoptera (Insecta). Biological Reviews of the Cambridge Philosophical Society 75, 129-167.

DOI 10.1146/annurev.en.26.010181.001535

ZhANG, J. 1999. Aeschnidiid nymphs from the Jehol biota (latest Jurassic-Early Cretaceous), China, with a discussion of the family Aeschnidiidae (Insecta, Odonata). Cretaceous Research 20,813-827. DOI 10.1006/cres.1999.0189

ZHANG, J. 2000. The discovery of aeschnidiid nymphs (Aeschnidiidae, Odonata, Insecta). Chinese Science Bulletin 45, 1031-1038. DOI 10.1007/BF02884986

ZhANG, J. \& Zhang, H. 2001. New findings of larval and adult aeschnidiids (Insecta: Odonata) in the Yixian Formation, Liaoning Province, China. Cretaceous Research 22, 443-450. DOI 10.1006/cres.2001.0273 